\title{
Pathogenic Attributes of Non-Candida albicans Candida Species Revealed by SEM
}

\author{
Márcia Cristina Furlaneto ${ }^{1}$, Célia Guadalupe Tardeli de Jesus Andrade², \\ Luciana Furlaneto-Maia ${ }^{3}$, Emanuele Júlio Galvão de França ${ }^{1}$ \\ and Alane Tatiana Pereira Moralez ${ }^{1}$ \\ ${ }^{1}$ Department of Microbiology, \\ ${ }^{2}$ Electronic Microscopy and Microanalysis Laboratory, \\ State University of Londrina (UEL), \\ ${ }^{3}$ Technological Federal University of Paraná (UTFPR), Londrina-PR, \\ Brazil
}

\section{Introduction}

The advent of microscopy provided an expressive progress on the knowledge of the biological world. Particularly important was the development of the electron microscopy at 1930s, making possible to find out a universe of unimaginable dimensions. Its great highlight is the much shorter wavelength of the electron that increases the resolution power of the equipment (Lee, 1993). Currently the electron microscopy is considered a specialized field of science (Bozzola and Russel, 1999). Although electron microscopy is useful to answer important questions about the ultrastructure of biological materials, it is also represent an additional tool that may be used as an ally in several research fields.

The scanning electron microscope (SEM) is useful to analyze microstructural features of solid bodies' surfaces, such as yeast cells. Besides, it leads to the formation of a threedimensional image as a direct result of the great depth of field (Lee, 1993). Even samples observed by naked eye may be analyzed at low magnifications with great depth of focus, making possible to obtain images with a pronounced resolution using detectors of secondary electrons. Thus, the electron microscopy may contribute to reveal this nanometer's world including fungal cell structure and the interaction between fungal cells and their microenviroment.

Most of the ultrastructural studies of Candida are based on the polymorphic species Candida albicans. In a pioneering study, the employment of SEM allowed the analyses of the surface features of different morphologies (budding yeast cells, germ tubes, hyphae and chlamydospores) of C. albicans (Barnes et al., 1971). Since then, many studies have applied SEM to elucidate several biological features of Candida. Recently, an updated useful review of the ultrastructural biological features of superficial candidiasis was presented (Jayatilake, 2011).

The evolution of intensive care medicine prolongs life expectancy leading populations to high susceptibility for candidal infection. Although ubiquitous in nature, Candida species 
can cause various infections that can vary from a relatively mild skin mycoses to lifethreatening systemic disease. Over the past two decades, an increase in the number of cases caused by non-Candida albicans Candida (NCAC) species has been reported. In this context, Candida parapsilosis and Candida tropicalis are among the commonest species of Candida responsible for nosocomial blood infection worldwide (Krcmery \& Barnes, 2002, Almirante et al., 2006, Colombo et al., 2006, Nucci \& Colombo, 2007). Besides, C. parapsilosis has gained increasing recognition as the most common etiological agent causing Candida nail infections (reviewed in Trofa et al., 2008).

Yeasts belonging to genus Candida produce daughter cells by budding that readily separate at sites of septation. However other morphologies also occur, including pseudohyphal cells that also grow by budding and display distinct constrictions at septa, although they are more elongated and do not readily separate, and true hyphal cells formed as long thin tubes with parallel cell walls that lack septal constrictions.

With reference to morphological characteristics, Candida budding cells display oval, round, or cylindrical shapes. C. parapsilosis does not form true hyphae and exists in either a yeast phase or a pseudohyphal form. Differently, C. tropicalis can exist in multiple morphogenetic forms, including yeast phase, pseudohyphae and true hyphae, being considered a polymorphic fungi.

For pathogenic yeasts, it is widely accepted that yeast form cells are essential for efficient dissemination through the body, whereas the filamentous forms are required for tissue invasion. For C. albicans, strains lacking hyphal formation exhibited lower ability to invade tissue compared with wild-type strains (Jayatilake et al., 2006).

Most pathogenic Candida species have developed a wide range of putative virulence factors to assist in their ability to colonize host tissues, cause disease, and overcome host defenses. Despite intensive research to identify pathogenic factors in yeast, particularly in C. albicans, relatively little is known about the virulence attributes associated with NCAC species. Although non-albicans species seem to share common virulence determinants with $C$. albicans it is believed that they have a particular repertoire of specific virulence traits (Haynes, 2001). Currently, we still have much to learn about the virulence of NCAC species, particularly C. parapsilosis and C. tropicalis.

The purpose of this chapter is to sum up some of the recent ultrastructural findings of $C$. parapsilosis and $C$. tropicalis virulence-associated characteristics that are thought to contribute in their process of pathogenesis.

\section{Ultrastructural features of pathogenic attributes}

Multiple characteristics have been proposed to be putative virulence factors related to the pathogenesis of $C$. parapsilosis and C. tropicalis, including adherence to host surfaces (cells and tissues) and medical devices, formation of filamentous forms, biofilm formation, production of hydrolytic enzymes and phenotypic switching (reviewed in Trofa et al., 2008, reviewed in van Asbeck et al., 2009, reviewed in Silva et al., 2011).

Recently, França et al. (2010) described a correlation between in vitro haemolytic and proteinase activities in clinical isolates of $C$. parapsilosis and C. tropicalis and site of fungal 
isolation. According to these authors, anatomical sites of isolation seem to be correlated with these activities, particularly for C. parapsilosis isolates.

Currently, we are employing the SEM to evaluate many events related to pathogenicity of clinical strains of $C$. parapasilosis and C. tropicalis, including adherence to biotic substrates, agar invasion capability, switching morphogenesis and morphological alterations of Candida cells by compounds from natural resources.

Precise imaging of yeasts depends on the adequate preservation. To SEM analysis, yeast samples are well fixed by immersion on glutaraldehyde in phosphate buffer at proper concentrations (Hayat, 2000). The use of buffered osmium tetroxide at 1\%, for 1 hour, is recommended as post fixation to preserve cellular content and surfaces. In our studies, samples of planktonic cells or biofilms are critical point dried after ethanolic dehydration. In order to preserve the colonies organization some steps were optimized, such as omission of osmium tetroxide, ethanolic dehydration and critical point dried. As a routine in our laboratory colonies are freeze-dried to avoid distortions and to maintain their architecture. Besides, sputtering was performed using a thick layer $(50 \mathrm{~nm})$ of gold.

\subsection{Adherence patterns in vitro}

Adherence is essential for members of the genus Candida to develop their pathogenic potential since it triggers the process that leads to colonization and allows their persistence in the host. Furthermore, different intra-species adherence ability has been reported for Candida species (reviewed in Silva et al., 2011). For instance, C. tropicalis exhibited higher ability to colonize reconstituted human epithelium (RHE) than did C. parapsilosis and Candida glabrata (Jayatilake et al., 2006). Adherence of C. albicans to epithelial cells is greater than that of C. parapsilosis (Lima-Neto et al., 2011).

For C. parapsilosis its emergence as a major opportunistic and nosocomial pathogen may relate to an ability to colonize the skin and adhere to inert polymeric surfaces and forms biofilms on these surfaces, such as catheters, prosthetic valves, artificial dentures and others (Douglas, 2003). According to Panagoda et al. (2001) the initial adherence of C. parapsilosis to surfaces is associated with cell surface hydrophobicity.

As cited previously, C. parapsilosis is a common etiological agent causing Candida nail infections. In Brazil, C. parapsilosis is the first or second most common cause of onychomycosis lesions (Figueiredo et al., 2007, Martins et al. 2007). Candidal onychomycosis, infection affecting nails, is increasingly found especially in immunocompromised patients. Far more than being a simple esthetics problem, infected nail serves as a reservoir of infections of the skin and mucous membrane. Multiple virulence mechanisms of Candida are involved in the pathogenesis of nail infections (reviewed in Jayatilake et al., 2009).

Therefore, ultrastructural investigations of the interface of C. parapsilosis and the keratinised substrates from human source reveal important features, which may help to clarify the pathogenesis of superficial candidiasis.

We have recently initiated experiments to verify the in vitro adherence pattern of $C$. parapsilosis sensu stricto (formerly C. parapsilosis group I) isolates obtained from candidal onychomycosis with keratinous substrates from human source. In a recent work, SEM was employed to verify the capability of $C$. parapsilosis cells to adhere and grow as biofilm on 
human natural substrates (nail and hair). In addition, the adherence pattern of isolates exhibiting distinct colonies phenotypes (smooth and crepe) was compared (Oliveira et al. 2010). This analysis allowed us to observe, for the first time, extracellular material and biofilm formation by C. parapsilsois on keratinised substrates.

In the present study, we compared ultrastructural features related to adhesion of $C$. parapsilosis cells of isolates obtained from distinct clinical sources (nail infection and tracheal secretion), on soft keratin (cutaneous stratum corneum - the outermost layer of skin) and hard keratin (nail and hair) substrates, following growth on these substrates as sole nitrogen source. In general, the surfaces of the budding cells (blastoconidia) and pseudohyphae were generally smooth except for occasional bud scars. Based on the SEM images, a different pattern of adhesion was observed for the isolates tested (Figure 1). For the onychomycosis (finger nail lesion) isolate the cell population attached to keratin substrates consisted mainly of cells in the budding-yeast phase of growth (blastoconidia) (Figure 1 A1, B1 and C1). Besides, on stratum corneum keratin short hyphal form was observed (Fig. 1A1). Differently, the isolate obtained from tracheal secretion (colonization site) the cellular population consisted mostly of pseudohyphae, particularly on stratum corneum (Figure 1 A2), a pattern that could indicate that this situation favors cellular morphologies with capacity for tissue invasion. Furthermore, SEM analysis also revealed that the tracheal secretion isolate presented different morphological pattern according to the substrate that they were in contact. For instance, cells adhered to hair keratin, consisted mainly of blastoconidia (Figure 1 C2). Overall, there was a loose association between yeast cells and keratinous substrates. However, on stratum corneum extracellular material was seen evolving cells from the onychomycosis isolate by forming a biofilm-like structure (Fig. 1A1). This feature was not observed on the other two sources of human keratin (nail and hair). These results extend our knowledge about the course of adhesion of C. parapsilosis on keratinized substrates which may help to clarify the pathogenesis of superficial candidiasis.

\subsection{Invasion capability}

Morphogenesis between yeast and hyphal growth, which facilitates fungal tissue invasion and enables the fungus to evade the defense system of the host is generally accepted as virulence traits of C. albicans. For instance, Jayatilake et al. $(2008,2009)$ have demonstrated that multiple host-fungal interactions such as cavitations, thigmotropism, and morphogenesis take place during candidal tissue invasion.

For non-albicans Candida species it is suggested that filamentous forms (hyphae and/or pseudohyphae) also assist in the invasive penetration of physical barriers (reviewed in Jayatilake, 2011). However, relatively little is known about the invasive potential regarding NCAC species. According to the literature, the invasiveness of non-albicans Candida species is variable among species. For instance, in RHE model C. tropicalis exhibited higher ability to invade this tissue than did C. parapsilosis and C. glabrata (Jayatilake et al., 2006).

Although it is well established that $C$. tropicalis is a polymorphic fungus few studies have analyzed the importance of its morphology on virulence. Recently, Silva et al. (2010) demonstrated that only filamentous forms of C. tropicalis were able to invade an oral epithelium. 


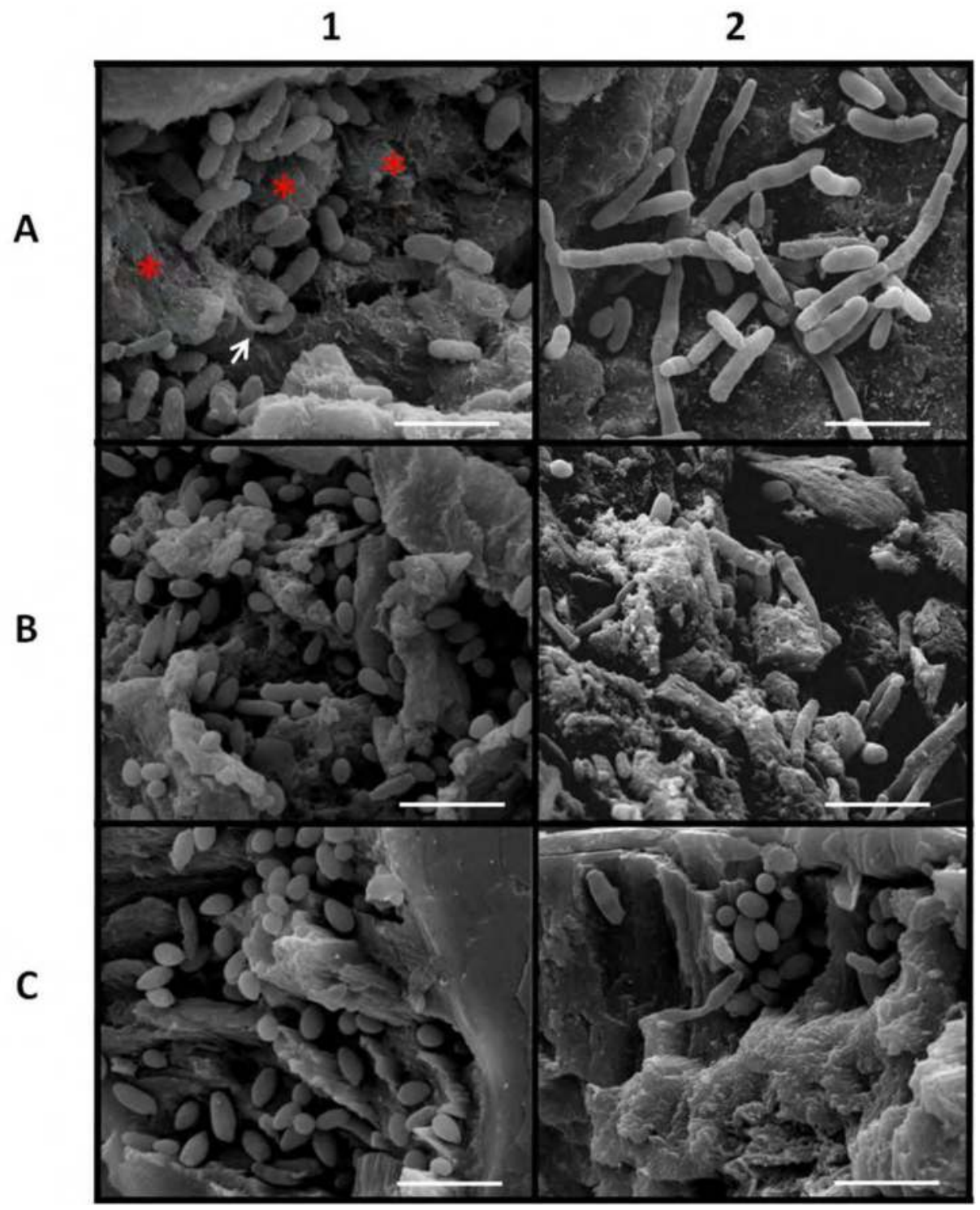

Fig. 1. These figures illustrate the in vitro adherence pattern of Candida parapsilosis isolates recovered from onychomycoses (1) and tracheal secretion (2) to human keratinous substrates. (A) Stratum corneum. On this substrate the cellular shape and the extend of extracellular material $\left(^{*}\right)$ were isolate-dependent. Note that cells from the onychomycosis isolate exhibits an oval shape while that cells from the tracheal secretion isolate displays pseudohyphae forms. (B) Nail. The pattern of cell morphology on nail keratin was also isolate-dependent. (C) Hair. The cellular features were independent to the site of yeast isolation. Short hyphal form (arrow). Scale bars $=100 \mu \mathrm{m}$. 
According to Brown et al. (1999), C. albicans cells respond to growth in contact with agar (semi solid matrix) medium by producing filaments that invade the agar. Production of invasive hyphae during growth in synthetic medium may occur by the same mechanism that is involved in production of invasive lesions during candidiasis. Recently, it has been showed that invasive filamentation of C. albicans into agar medium is promoted by a cell wall-linked protein (Zucchi et al., 2011). Thus, agar invasion tests enable sorting strains by their degree of invasiveness.

In this study, we employed the agar invasion assay to determine the invasive potential of a switch variant strain, exhibiting a crepe morphotype (Figure 2A), obtained from a clinical $C$. tropicalis isolate recovered from tracheal secretion. For this, cells were grown on the surface of YPD medium for 4 days a $37^{\circ} \mathrm{C}$. After colony were washed off the agar surface, with a stream of water and gentle rubbing, cells that had invaded the agar remained as macroscopically visible microcolonies on the surface of the washed plate (Fig. 2B). The parental isolate also invade, although not to the same extent (data not shown). This data suggests that colonies of $C$. tropicalis exhibiting distinct morphologies differ in their capabilities to invade agar. Similar data were observed by C. parapsilosis (Laffey and Bluter, 2005) using the agar invasion assay.

Further we analyzed the invaded agar at ultrastructural level, by the employment of fracture technique. Fracture is valuable to reveal internal surfaces and it is performed by dipping the fixed samples in liquid nitrogen and breaking with a sharp scalpel. Growth in YPD shows filamentous forms invading the agar at different planes and angles, as well as yeast cell forms (Figure 3). Thus, SEM may be useful for the detailed analysis of extend and pattern of yeast cells in the course of the invasion process. This is the first report of the employment of SEM to examine the pattern of agar invasion by Candida cells.

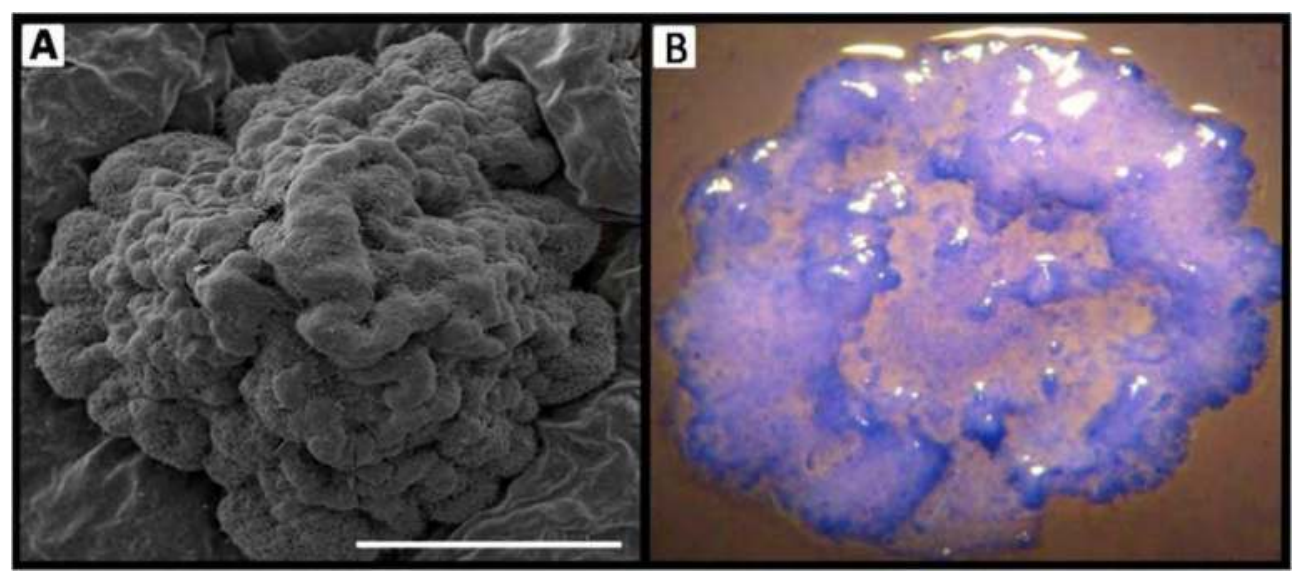

Fig. 2. (A) Scanning electron micrograph shows C. tropicalis morphotype crepe following 96 $h$ growth on YPD agar. (B) Photomicrograph of footprint of attached cells after washing out the colony. Scale bar $=1 \mathrm{~mm}(\mathrm{~A})$. 2.5X (B). 


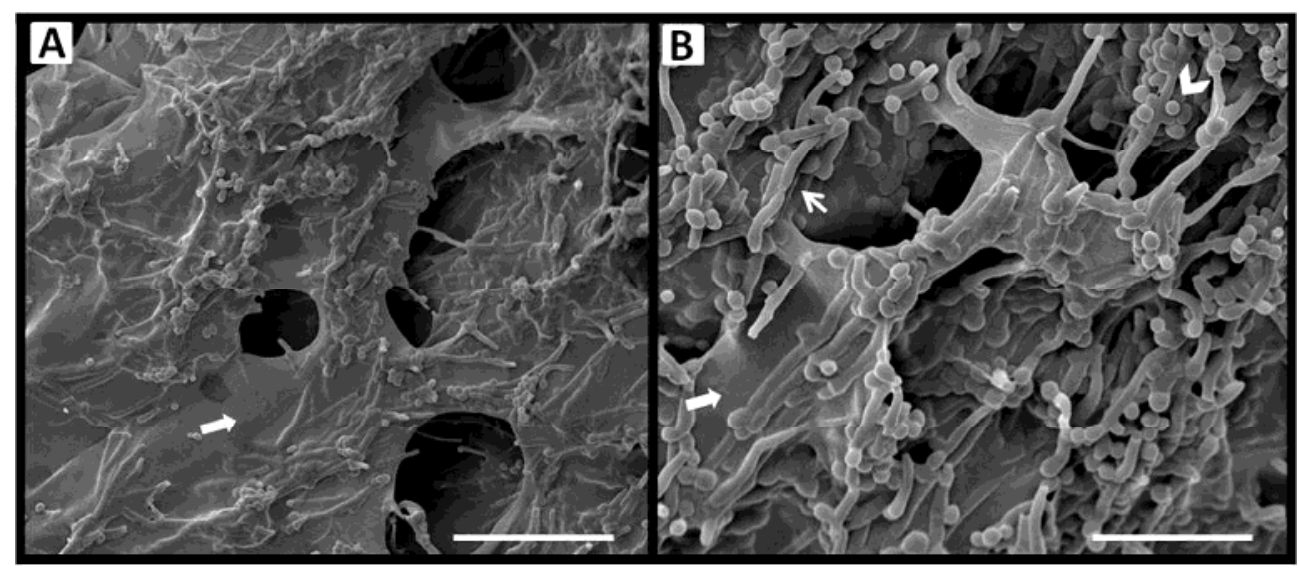

Fig. 3. Scanning electron micrographs of agar invasion by $C$. tropicalis crepe after cells were washed off the agar surface. Cells includes on agar substrate (large arrow) appear like filamentous form (thin arrow) and blastoconidia (head arrow) Scale bars $=100 \mu \mathrm{m}(\mathrm{A})$ and $50 \mu \mathrm{m}(\mathrm{B})$.

\subsection{Switching morphotypes: Ultrastructure and morphological types}

Phenotypic switching represents an epigenetic state that occurs in a small fraction of the population, is random and reversible. This biological phenomenon is related to the occurrence of spontaneous emergence of colonies with different morphologies that enables the microorganism to undergo rapid microevolution and to adapt to different environments, including various anatomical sites in the human body (reviewed in Soll, 1992). Thus, the switching phenotype event has also being considered a candidal virulence factor (Segal, 2004).

Furthermore, switching has been demonstrated to regulate virulence-associated characteristics in C. albicans, such as adhesion, expression of cell surface hydrophobicity and biofilm formation (Kennedy et al., 1988, Antony et al., 2009, Lohse and Johnson, 2009). Concerning NCAC species, C. parapsilosis distinct switch phenotypes exhibited differential ability to form biofilm on polystyrene surfaces (Laffey and Butler, 2005). For C. tropicalis, França et al. (2010) also found a correlation in phenotypic switching and biofilm formation.

For fungi this event is defined as the reversible change manifested as altered colony morphology at a rate higher than the somatic mutation rate (reviewed in Soll, 1992).

In yeast, phenotypic switching was originally described in C. albicans strains (Soll, 1992), but is also known to exist in other Candida species, such as C. tropicalis (Soll et al., 1988, França et al., 2010).

Ultrastructural investigations revealed a relationship between $C$. albicans switched variant colonies and microstructure (Radford et al., 1994, 1997). In a pioneer study we report the presence of extracellular material, resembling a biofim-like colony, throughout the development of $C$. tropicalis switch colonies, suggesting that its presence is correlated with the complex architecture of colonies (França et al. 2010). 
SEM was successfully employed for the analyses of whole Candida colonies architecture (França et al. 2010, Furlaneto et al., 2012). Additional studies on switching event in clinical isolates of $C$. tropicalis are in progress. For instance, different architectures exhibited by $C$. tropicalis colonies morphotypes are shown in Figure 4. The smooth phenotype colony (Figure 4A) showed a hemispherical shape character, while the rough phenotype exhibited more complex architecture and was characterized by the presence of deep central and peripheral depressions areas (Figure 4B). The irregular wrinkled colony was characterized by a highly wrinkled centre and an irregular periphery (Figure $4 \mathrm{C}$ ). Crepe colony was characterized by the presence of aerial hyphae on the colony surface (Figure 4D). The preparation of colonies by a freeze-drying technique allowed their architecture preservation with maintenance of the phenotypes observed at lower magnitude (data not shown).

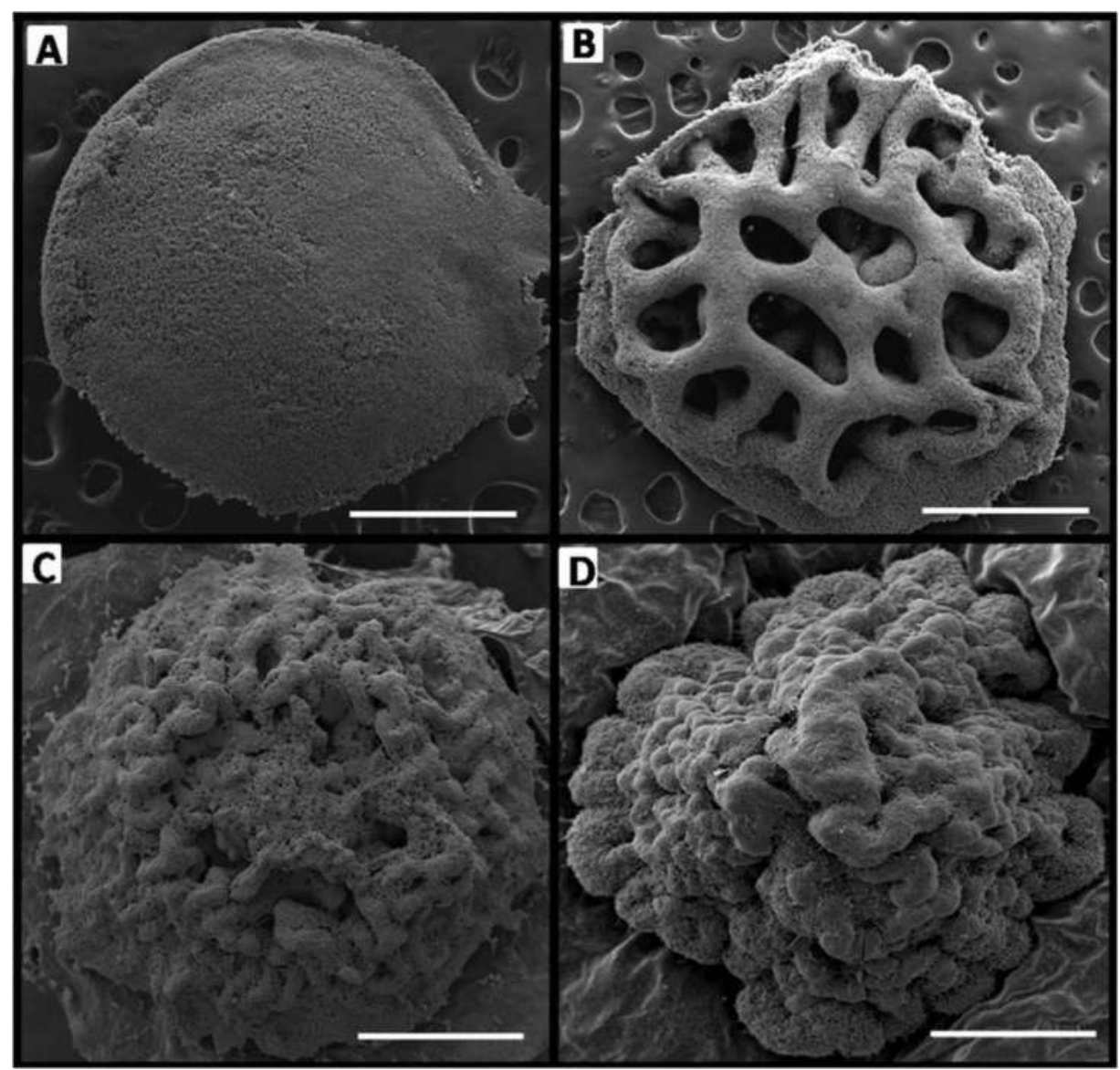

Fig. 4. Different architectures exhibited by C. tropicalis colonies morphotypes following $96 \mathrm{~h}$ incubation on YPD agar. (A) Smooth colony. (B) Rough colony, shows cells in a tridimensional disposition. (C) Cells are establishing an irregular wrinkled colony and (D) crepe colony shows the homogeneous substance coating its surface, besides filamentous forms. Scale bars $=1 \mathrm{~mm}$. 
The ultrastructural analysis allowed the observation of the arrangement of individual cells within the colonies. After 4 days of colony development, the whole smooth and irregular wrinkled colonies consisted entirely of yeast cells (not shown). The crepe colony phenotype also comprised mainly yeast cells as observed at depressions areas (Figure 5A). Most interesting was the presence of extracellular material forming a biofilm-like colony where many of the cells were almost hidden by this material. It was observed as fibrils, with enlarged structures, connecting neighbouring cells (Figure 5B).

A C. tropicalis variant exhibiting a myceliated phenotype is shown in Figure 6. The whole colony surface is formed by aerial mycelia with a prominent centre (Figure 6A). The aerial hyphae showed a compact nature that is composed by hyphae and blastoconidia (Figure 6B).

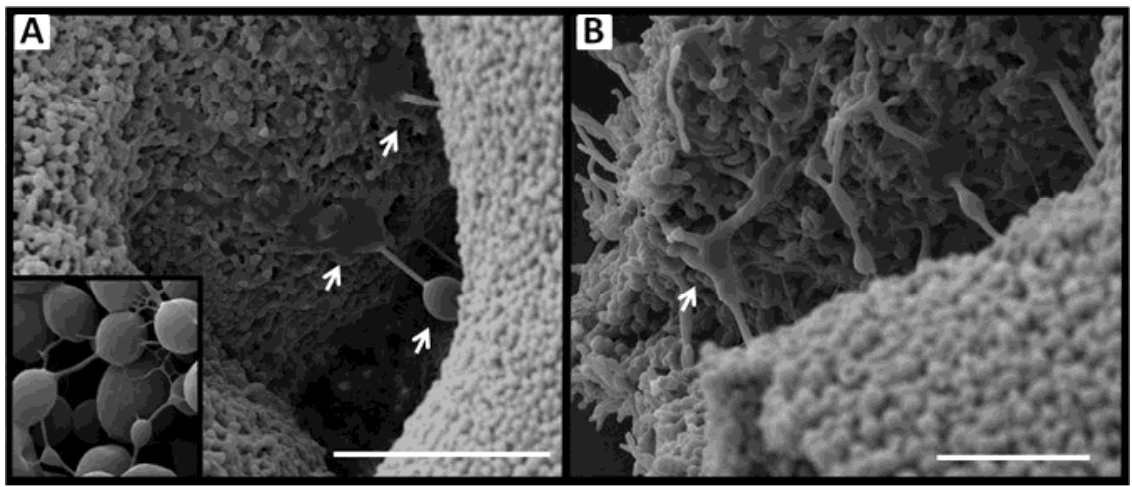

Fig. 5. C. tropicalis crepe morphotype following $96 \mathrm{~h}$ incubation on YPD agar.

(A) Extracellular material (arrows) is seeing forming a biofilm-like colony. (B) Fractured colonies reveal details of extracellular material recovering and connecting cells. Scale bar $=100 \mu \mathrm{m}(\mathrm{A}), 50 \mu \mathrm{m}(\mathrm{B})$. Inset shows fibrilar extracellular material connecting cells (5000x)

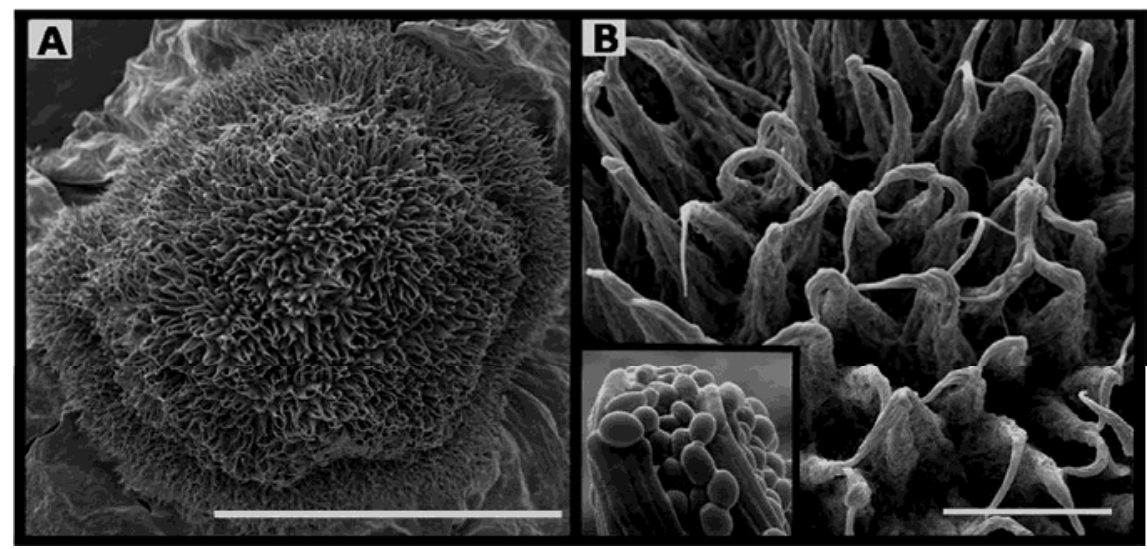

Fig. 6. Electron micrographs of the C. tropicalis myceliated morphotype following $96 \mathrm{~h}$ incubation on YPD agar. (A) Whole myceliated colony, (B) In higher magnification aerial hyphae showing compact nature. Scale bars $=1 \mathrm{~mm}(\mathrm{~A}), 100 \mu \mathrm{m}(\mathrm{B})$. Inset shows detail of a distal end of an aerial hyphae that is composed by hyphae and blastoconidia (5000x) 


\subsection{Effect of antifungal compounds on yeast morphology}

The therapy of deep fungal infections, particularly those caused by opportunistic pathogens, including Candida species, remains a difficult medical problem. Besides, compared with antibiotics, the development of antifungal agents has been relatively limited. Widespread use of antifungal agents could be an explanation for the emergence of the more resistant non-albicans species of Candida (Pfaller \& Diekema, 2004). Fluconazole is a systemic antifungal drug effective against most of the Candida species; however, the emergence of fluconazole resistance has been reported in NCAC species, particularly C. tropicalis and C. parapsilosis (Yang et al., 2004, Pereira et al., 2010, Oxman et al., 2010, Bruder-Nascimento et al., 2010). The emergence of yeast species with decreased susceptibility to contemporary antifungal regimens demonstrates the need for new antifungal agents.

Many studies have addressed the search for natural compounds with antifungal activity. As an example, Duarte et al. (2005) screened 35 medicinal plants commonly used in Brazil for anti-Candida albicans activity. In this context, the flavonoid baicalein, originally isolated from the roots of Scutellaria baicalensis Georgi (a Chinese herb) has been tested against C. albicans (Cao et al., 2008, Huang et al., 2008). According to these authors, antifungal activity was observed on free cells as well as on biofilm.

Ultrastructural investigations of the effect of natural compounds on morphology are limited. However, SEM analysis allowed the observation of irregular budding patterns and pseudohyphae formation in C. albicans type strain treated with compounds isolated from pomegranate peels (Endo et al., 2010). In contrast, the exposure of cells from the same type strain to berberine (alkaloid found in medicinal herbs) did not affect cell morphology (Iwazaki et al., 2010).

We employed the scanning electron microscopy to evaluate the effect of baicalein alone and in combination with fluconazole on the morphology of C. parapsilosis and C. tropicalis. For C. parapsilosis, SEM analyses showed control cells (untreated cells) with a normal budding profile where no extracellular material was seen (not shown). After exposure to baicalein alone, the general aspect of the cells was not modified, however, a profusely flocculent extracellular material was seeing connecting yeast cells (Fig. 7A). Similar pattern was observed for cells exposed to baicalein in combination with fluconazole, although, the amount of extracellular was visible higher (Fig. 7B). SEM images also showed markedly reduced number of organisms due to baicalein.

On the other hand, the data obtained in this study showed that C. tropicalis underwent morphological alterations visible by SEM when treated with subinhibitory concentration of baicalein alone and in association with fluconazole.

Untreated cells (control) consisted of blastoconidia and pseudohyphae (not shown). For cells exposed to baicalein alone we observed the presence of elongated cells as well as a great capacity for producing pseudohyphae (Fig. 8A). Cells exposed to baicalein in combination with fluconazole showed an oval shape with profusely flocculent extracellular material connecting yeast cells (Fig. 8B). These data, suggest different inter-species response to baicalein alone as well as to in association with fluconazole. 


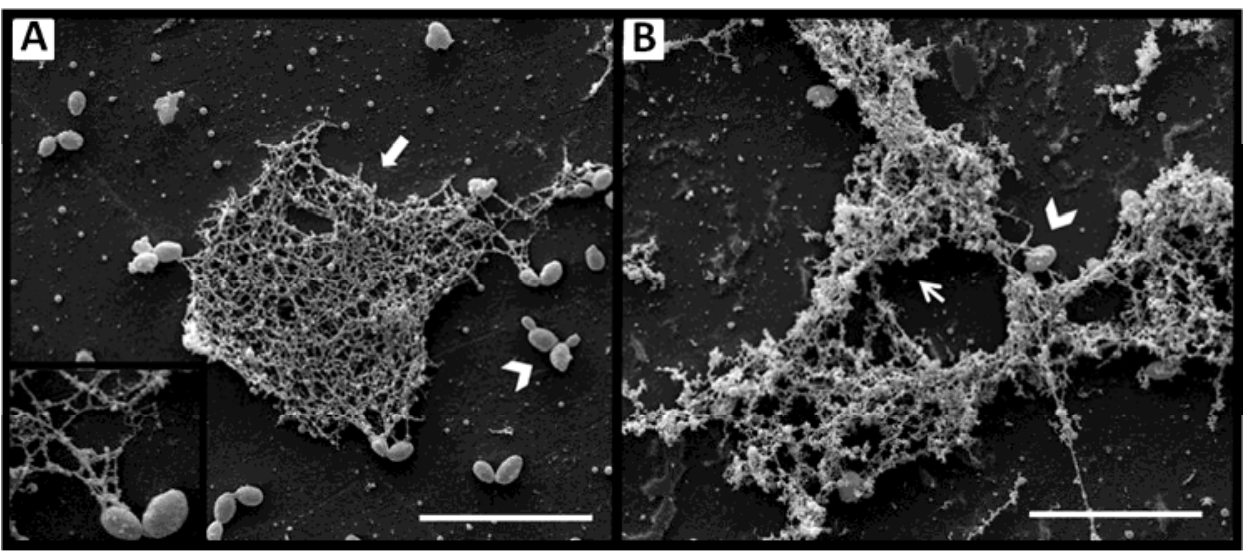

Fig. 7. C. parapsilosis treated with baicalein alone (MIC50) and in combination with fluconazole. (A) baicalein, (B) baicalein plus fluconazole. C. parapsilosis cells display a typical oval shape (heads arrow). Some of them are involved by an extracellular material constituted by irregular fibrils disposed as a network (large arrow). Note that fibrils appear like beads on a string (inset). In B, a flocculent extracellular material (thin arrow) is seeing connecting cells. Scale bar $=20 \mu \mathrm{m}$. Inset $=12,000 \mathrm{X}$

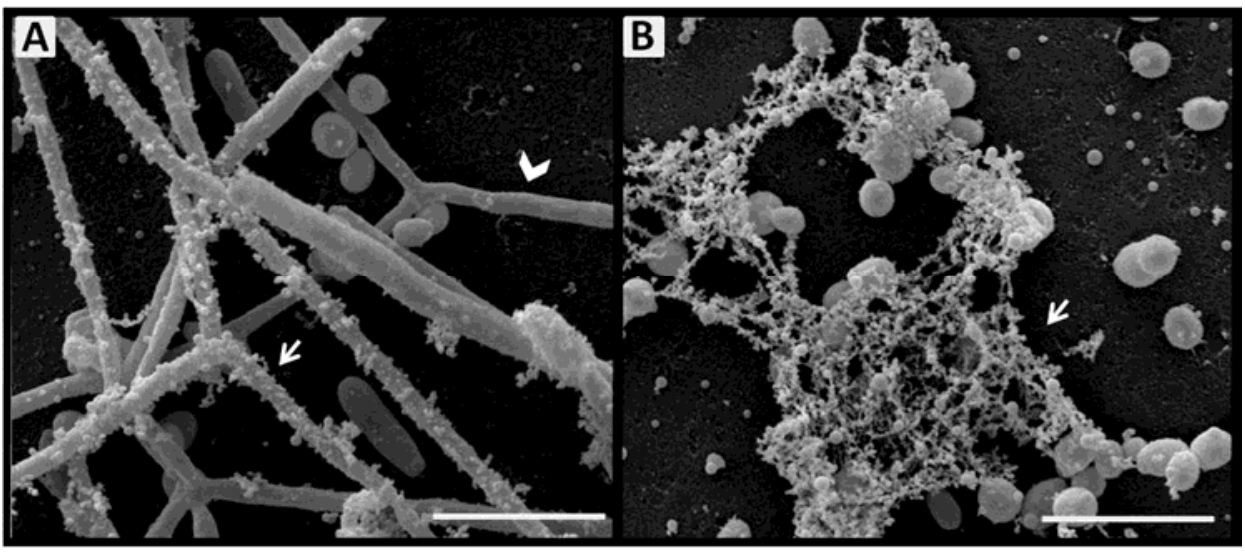

Fig. 8. C. tropicalis treated with baicalein alone (A) and in combination with fluconazole (B). Hyphae form is predominant in treatment with baicalein (head arrow), while in combination with antifungal blastoconidia prevails. Flocculent extracellular material (arrows) is seen surrounding hyphae and a prominent one is connecting blastoconidia. Scale bar $=20 \mu \mathrm{m}$.

\section{Conclusion}

Yeast pathogenicity arises through complex interactions between the organism's virulence characteristics and the host's response. Candida species can exhibit several virulence factors such as adherence, biofilm formation and phenotypic switching that increase their persistence within the host as well as allow adapting to different anatomical sites in the 
human body. Therefore, the increase in the incidence and antifungal resistance of NCAC species, specifically, C. parapsilosis and C. tropicalis, and the unacceptably high morbidity and mortality associated with these species, make it essential to further enhance our knowledge on the virulence and resistance mechanisms associated with these species. An understanding of the virulence determinants of these species would provide insight into their pathogenic mechanisms. Our studies have shown that ultrastructural investigations at SEM of some of these virulence traits may help to elucidate general mechanisms of fungal virulence. Another approach that is in progress in our laboratory is the processing of yeast samples to analyse at transmission electron microscopy that may reveal inner ultrastructure at higher resolution.

\section{Acknowledgments}

The author gratefully acknowledges to all colleagues and students joined to the medical mycology group at State University of Londrina and Technological Federal University of Paraná in Londrina, Paraná-Brazil. Special thanks to the group members: Ana Flávia Leal Specian and Rosapa Serpa that contributed with results obtained during their master thesis work. The authors also thank Osvaldo Capello for technical support. Team's members using original results made all the figures' composition. This work was partially supported by Conselho Nacional de Desenvolvimento Científico e Tecnológico-CNPq-Brazil.

\section{References}

Anthony, G.; Saralaya, V.; Gopalkrishna Bhat, K; Shalini Shenoy, M. \& Shivananda, P.G. (2009). Effect of phenotypic switching on expression of virulence factors by Candida albicans causing candidiasis in diabetic patients. Revista Iberoamericana de Micologia, Vol.26, No.3 (September 2009), pp. 202-205, ISSN 1130-1406.

Almirante, B.; Rodríguez, D. \& Cuenca-Estrella, M. (2006). Epidemiology, risk factors, and prognosis of Candida parapsilosis bloodstream infections: case-control populationbased surveillance study of patients in Barcelona, Spain, from 2002 to 2003. Journal of Clinical Microbiology, Vol.44, No.5 (May2006), pp. 1681-1685, ISSN 0095-1137.

Barnes, W.G.; Flesher, A.; Berger, A.E. \& Arnold, D.J. (1971). Scanning electron microscopic studies of Candida albicans. Journal of Bacteriology, Vol.106, No.1 (April 1971), pp. 276-280, ISSN 0021-9193.

Bozzola, J.J. \& Russel, L.D. 1999. Electron microscopy. Principles and Techniques for Biologists. $\left(2^{\text {nd }}\right.$ ed.), Jones and Bartlett Publishers, ISBN 0-7637-0192-0, Sudbury, Massachusetts, USA.

Branchini, M.L.; Pfaller, M.A.; Rhine-Chalberg, J.; Frempong, T. \& Isenberg, H.D. (1994). Genotypic variation and slime production among blood and catheter isolates of Candida parapsilosis. Journal of Clinical Microbiology, Vol.32, No.2 (February 1994), pp. 452-456, ISSN 0095-1137.

Brown, D.H.Jr.; Giusani, A.D.; Chen, X. \& Kumamoto, C.A. (1999). Filamentous growth of Candida albicans in response to physical environmental cues and its regulation by the unique CZF1 gene. Molecular Microbiology, Vol.34, No.4 (November 1999), pp. 651-662, ISSN 1365-2958.

Bruder-Nascimento, A.; Camargo, C.H.; Sugizaki, M.F.; Sadatsune, T.; Montelli, A.C.; Mondelli, A.L.; Bagagli, E. (2010). Species distribution and susceptibility profile of 
Candida species in a Brazilian public tertiary hospital. BCM Research Notes, Vol.3, No.1 (January 2010), pp. 1-5, ISSN 1756-0500.

Cao, Y.Y.; Dai, B.D.; Wang, Y.; Huang, S.; Xu, Y.G.; Cão, Y.B.; Gao, P.H.; Zhu, Z.Y. \& Jiang, Y.Y. (2008). In vitro activity of baicalein against Candida albicans biofilms. International Journal of Antimicrobial Agents, Vol.32, No.1 (July 2008), pp. 73-77, ISSN 0924-8579.

Colombo, A.L.; Nucci, M.; Park, B.J.; Nouer, A.S.; Arthington-Skaggs, B.; da Matta, D.A.; Warnock, D. \& Morgan, J. (2006). Epidemiology of candidemia in Brazil: a nationwide sentinel surveillance of candidemia in eleven medical Centers. Journal of Clinical Microbiology, Vol.44: No.8 (August 2006), pp. 2816-23, ISSN 0095-1137.

De Bernardis, F.; Mondello, F.; San Millàn, R.; Ponón J. \& Cassone, A. (1999). Biotyping and virulence properties of skin isolates of Candida parapsilosis. Journal of Clinical Microbiology, Vol.37, No.11 (November 1999), pp. 3481-3486, ISSN 0095-1137.

Douglas, J. (2003). Candida biofilms and their role in infection. Trends in Microbiolgy, Vol.11, No.1 (January 2003), pp.: 30-36, ISSN 0966-842X.

Duarte, M.C.T.; Figueira, G.M.; Sartoratto, A.; Rehder, V.L.G. \& Delarmelina C. (2005). AntiCandida activity of Brazilian medicinal plants. Journal of Ethnopharmacology, Vol.97, No.28 (February), pp. 305-311, ISSN 0378-8741.

Endo, E.H.; Cortez, D.A.G.; Ueda-Nakamura, T.; Nakamura, C.V. \& Filho, B.P.D. (2010). Potent antifungal activity of extracts and pure compound isolated from pomegranate peels and synergism with fluconazole against Candida albicans. Research in Microbiology, Vol.161, No.7 (September 2010), pp. 534-540, ISSN 09232508.

Figueiredo, V.T.; Santos, D.A.; Resende, M.A. \& Hamdan, J.S. (2007). Identification and in vitro antifungal susceptibility testing of 200 clinical isolates of Candida spp. responsible for fingernail infections. Mycopathologia, Vol.164, No.1 (June 2007), pp.27-33, ISSN 0301-486X.

França, E.J.G.; Andrade, C.G.T.J.; Furlaneto-Maia, L.; Serpa, R.; Oliveira, M.T.; Quesada, R.M.B. \& Furlaneto, M.C. (2011). Ultrastructural architecture of colonies of different morphologies and biofilm produced by phenotypic switching of Candida tropicalis. Micron, Vol.42, No.7 (October 2011), pp. 726-732, ISSN 0968-4328.

França, E.J.G.; Furlaneto-Maia, L.; Quesada, R.M.B.; Favero, D.; Oliveira, M.T. \& Furlaneto, M.C. (2010). Haemolytic and proteinase activities in clinical isolates of Candida parapsilosis and Candida tropicalis with reference to the isolation anatomic site. Mycoses, Vol.54, No.4 (July 2011), pp. e44-e51, ISSN 1439-0507.

Furlaneto, M.C.; Andrade, C.G.T.J.; Aragão, P.H.A.; França, E.J.G.; Moralez, A.T.P. \& Ferreira, L.C.S. (2012). Scanning Electron Microscopy as tool for the analyses of colonies architecture of different morphologies produced by phenotypic switching of a human pathogenic yeast Candida tropicalis. Journal of Physics. Conference Series, ISSN 1742-6588, in press.

Hayat, M.A. 2000. Principles and Techniques of Electron Microscopy. Biological Applications. (4th ed.), Cambridge University Press, ISBN 0-521-63287-0, USA.

Haynes, K. (2001). Virulence in Candida species. Trends in Microbiology, Vol.9, No.12 (December 2001), pp. 591-596, ISSN 0966-842X.

Huang, S.; Cao, Y.Y.; Dai, B.D.; Sun, X.R.; Zhu, Z.Y.; Cao, Y.B.; Wang, Y.; Gao, P.H. \& Jiang, Y.Y. (2008). In vitro synergism of fluconazole and baicalein against clinical isolates 
of Candida albicans resistant to fluconazole. Biological Pharmaceutical Bulletim, Vol.31, No.12 (December 2008), pp. 2234-2236, ISSN 1347-5215.

Iwazaki, R.S.; Endo, E.H.; Ueda-Nakamura, T.; Nakamura, C.V.; Garcia, L.B. \& Filho, B.P.D. (2010). In vitro antifungal activity of the berberine and its synergism with fluconazole. Antonie van Leeuwenhoek, Vol.97, No.2 (November 2009), pp. 201-205, ISSN 0003-6072.

Kennedy, M.J.; Rogers, A.L.; Hanselman, L.R.; Soll, D.R. \& Yancey, R.J. (1988). Variation in adhesion and cell surface hydrophobicity in Candida albicans white and opaque phenotypes. Mycopathologia, Vol.102, No.3 (June 1988), pp. 149-156, ISSN 0301-486X.

Jayatilake, J.A.M.S. (2011). A review of the ultrastructural features of superficial candidiasis. Mycopathologia, Vol.171, No.4 (October 2010), pp. 235-250, ISSN 0301-486X.

Jayatilake, J.A.; Samaranayake, Y.H.; Cheung, L.K. \& Samaranayake, L.P. (2006). Quantitative evaluation of tissue invasion by wild type, hyphal and SAP mutants of Candida albicans, and non-albicans Candida species in reconstituted human oral epithelium. Journal of Oral Pathology and Medicine, Vol.35, No. 8 (August 2006), pp. 481-491, ISSN 1600-0714.

Jayatilake, J.A.M.; Samaranayake, Y.H. \& Samaranayake, L.P. (2008). A comparative study of candidal invasion in rabbit tongue mucosal explants and reconstituted human oral epithelium. Mycopathologia, Vol.165, No.6 (March 2008), pp. 373-380, ISSN 0301-486X.

Jayatilake, J.A.M.; Tilakaratne, W.M. \& Panagoda, G. J. (2009). Candidal onychomycosis: A Mini-Review. Mycopathologia, Vol.168, No.4 (May 2009), pp. 165-173, ISSN 0301486X.

Krcmery, V. \& Barnes, A. (2002). Non-albicans Candida spp. causing fungaemia pathogenicity and antifungal resistance. Journal of Hospital Infection, Vol.50, No.4 (April 2002), pp. 243-260, ISSN 0195-6701.

Laffey, S.F. \& Butler, G. (2005). Phenotype switching affects biofilm formation by Candida parapsilosis. Microbiology, Vol.151, No.4 (January 2005), pp. 1073-1082, ISSN 00027739.

Lee, R.E. 1993. Scanning Electron Microscopy and X-Ray Microanalysis. PTR Prentice-Hall, ISBN 0-13-813759-5, New Jersey, USA.

Lima-Neto, R.G.; Beltrão, E.I.; Oliveira, P.C. \& Neves, R.P. (2011). Adherence of Candida albicans and Candida parapsilosis to epithelial cells correlates with fungal cell surface carbohydrates. Mycoses, Vol.54, No.1 (January 2011), pp. 23-39, ISSN 0933-7407.

Lohse, M.B. \& Johnson, A.D. (2009). White-opaque switching in Candida albicans. Current Opininion in Microbiology, Vol.12, No. 6 (December 2009), pp. 650-654, ISSN 13695274.

Martins, E.A.; Guerrer, L.V.; Cunha, K.C.; Soares, M.M.C.; \& Almeida, M.T.G. (2007). Onychomycosis: clinical, epidemiological and mycological study in the municipality of São José do Rio Preto. Revista da Sociedade Brasileira de Medicina Tropical, Vol.40, No.5 (October 2007), pp. 596-598, ISSN 0037-8682.

Manzano-Gayosso, P.; Hernández-Hernández, F.; Méndez-Tovar, L.J.; Palacios-Morales, Y.; Córdova-Martínez, E.; Bazán-Mora, E. \& Martinez-López, R. (2008). Onychomycosis incidence in type 2 diabetes mellitus patients. Mycopathologia, Vol.166, No.1 (March 2008), pp. 41-45, ISSN 0301-486X. 
Nucci, C. \& Colombo, A.L. (2007). Candidemia due to Candida tropicalis: clinical, epidemiologic, and microbiologic characteristics of 188 episodes occurring in tertiary care hospitals. Diagnostic Microbiology and Infectious Diseases, Vol.58, No.1 (May 2007), pp. 77-82, ISSN 0732-8893.

Oliveira, M.T.; Specian, A.F.; Andrade, C.G.T.J.; França, E.J.G.; Furlaneto-Maia, L. \& Furlaneto, M.C. (2010). Interaction of Candida parapsilosis with human hair and nails surfaces revealed by scanning electron microscopy analysis. Micron, Vol.41, No.6 (August 2010), pp. 604-606, ISSN 0868-4328.

Oxman, D.A.; Chow, J.K.; Frendl, G.; Hadley, S.; Hershkovitz, S.; Ireland, P.; McDermott, L.A.; Tsai, K.; Marty, F.M.; Kontouiannis, D. \& Golan, Y. (2010). Candidaemia associated with decreased in vitro fluconazole susceptibility: is Candida speciation predictive of the susceptibility pattern? Journal of Antimicrobial Chemotherapy, Vol.65, No.7 (April 2010), pp. 1460-1465, ISSN 0305-7453.

Panagoda, G.J.; Ellepola, A.N. \& Samaranayake, L.P. (2001). Adhesion of Candida parapsilosis to epithelial and acrylic surfaces correlates with cell surface hydrophobicity. Mycoses, Vol.44, No.1-2 (March 2001), pp. 29-35, ISSN 1439-0507.

Pereira, G.H.; Mulles, P.R.; Szeszs, M.W.; Levin, A.S. \& Melhem, M.S.C. (2010). Five-year evaluation of bloodstream yeast infections in a tertiary hospital: the predominance of non-C. albicans Candida species. Medical Mycology, Vol.48, No.6 (September 2010), pp. 839-842, ISSN 1369-3786.

Pfaller, M.A. \& Diekema, D.J. (2004). Twelve years of fluconazole in clinical practice: global trends in species distribution and fluconazole susceptibility of bloodstream isolates of Candida. Clinical Microbiology and Infection, Vol.10, No.1 (January 2004), pp. 11-23.

Radford, D.R.; Challacombe, S.J. \& Walter, J.D. (1994). A scanning electron microscopy investigation of the structure of colonies of different morphologies produced by phenotypic switching of Candida albicans. Journal of Medical Microbiology, Vol.40, No.6 (June, 1994), pp. 416-423, ISSN 1473-5644.

Radford, D.R.; Challacombe, S.J. \& Walter, J.D. (1997). Scanning electron microscopy of the development of structured aerial mycelia and satellite colonies of phenotypically switched Candida albicans. Journal of Medical Microbiology, Vol.46, No. 4 (April, 1997), pp. 326-332, ISSN 1473-5644.

Segal, E. (2004). Candida, still number one - what do we know and where are we going from there? Mycoses, Vol.48, No.1 (April, 2005), pp. 3-11, ISSN 1439-0507.

Silva, S.; Hooper, S.J.; Henriques, M.; Oliveira, R.; Azeredo, J. \& Williams, D.W. (2010). The role of secreted aspartyl proteinases in Candida tropicalis invasion and damage of oral mucosa. Clinical Microbiology and Infection, Vol.17, No. 2 (April 2010), pp. 264272, ISSN 1469-0691.

Silva, S.; Negri, M.; Henriques, M.; Oliveira, R.; Williams, D.W. \& Azeredo, J. (2011). Adherence and biofilm formation of non-Candida albicans Candida species. Trends in Microbiology, Vol.19, No.5 (May 2011), pp. 241-247, ISSN 0966-842X.

Slutsky, B.; Buffo, J. \& Soll, D.R. (1985). High frequency switching of colony morphology in Candida albicans. Science, Vol.230, No. 4723 (November, 1985), pp. 666-669, ISSN 1535-9778.

Soll, D.R. (1992). High-frequency switching in Candida albicans. Clinical Microbiology Reviews, Vol.5, No.2 (April, 1992), pp. 183-203, ISSN 0893-8512. 
Soll, D.R.; Staebell, M.; Langtimm, C.; Pfaller, M.; Hicks, J. \& Gopala Rao, T.V. (1988). Multiple Candida strains in the course of a single systemic infection. Journal of Clinical Microbiology, Vol.26, No. 8 (August, 1988), pp. 1448-1459, ISSN 0095-1137.

Trofa, D.; Gácser, A. \& Nosanchuk, J.D. (2008). Candida parapsilosis: an emerging fungal pathogen. Clinical Microbiology Review, Vol.21, No.4 (October 2008), pp. 606-625, ISSN 0893-8512.

van Asbeck, E.C.; Clemins, K.V. \& Stevens, D.A. (2009) Candida parapsilosis: a review of its epidemiology, pathogenesis, clinical aspects, typing and antimicrobial susceptibility. Critical Review in Microbiology, Vol.35, No.4 (November, 2009), pp. 283-309, ISSN 1040-841X.

Yang, Y.L.; Ho, Y.A.; Cheng, H.H.; Ho, M. \& Lo, H.J. (2004). Susceptibilities of Candida species to amphotericin $\mathrm{B}$ and fluconazole: the emergence of fluconazole resistance in Candida tropicalis. Infection Control Hospital Epidemiology, Vol.25, No.1 (January, 2004), pp. 60-64, ISSN 0899-823X.

Zucchi, P.C.; Davis, T.R. \& Kumamoto, C.A. (2010). A Candida albicans cell wall-linked protein promotes invasive filamentation into semi-solid medium. Molecular Microbiology, Vol.76, No.3 (May 2010), pp. 733-748, ISSN 1365-2958. 


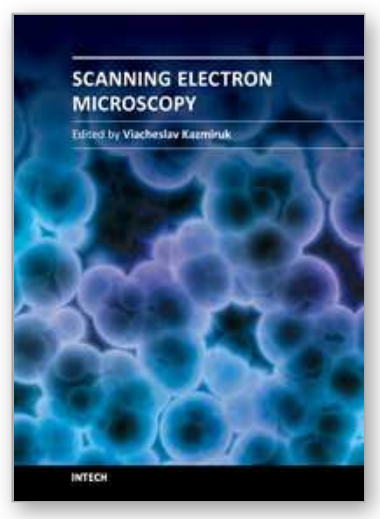

\author{
Scanning Electron Microscopy \\ Edited by Dr. Viacheslav Kazmiruk
}

ISBN 978-953-51-0092-8

Hard cover, 830 pages

Publisher InTech

Published online 09, March, 2012

Published in print edition March, 2012

Today, an individual would be hard-pressed to find any science field that does not employ methods and instruments based on the use of fine focused electron and ion beams. Well instrumented and supplemented with advanced methods and techniques, SEMs provide possibilities not only of surface imaging but quantitative measurement of object topologies, local electrophysical characteristics of semiconductor structures and performing elemental analysis. Moreover, a fine focused e-beam is widely used for the creation of micro and nanostructures. The book's approach covers both theoretical and practical issues related to scanning electron microscopy. The book has 41 chapters, divided into six sections: Instrumentation, Methodology, Biology, Medicine, Material Science, Nanostructured Materials for Electronic Industry, Thin Films, Membranes, Ceramic, Geoscience, and Mineralogy. Each chapter, written by different authors, is a complete work which presupposes that readers have some background knowledge on the subject.

\title{
How to reference
}

In order to correctly reference this scholarly work, feel free to copy and paste the following:

Márcia Cristina Furlaneto, Célia Guadalupe Tardeli de Jesus Andrade, Luciana Furlaneto-Maia, Emanuele Júlio Galvão de França and Alane Tatiana Pereira Moralez (2012). Pathogenic Attributes of Non-Candida albicans Candida Species Revealed by SEM, Scanning Electron Microscopy, Dr. Viacheslav Kazmiruk (Ed.), ISBN: 978-953-51-0092-8, InTech, Available from: http://www.intechopen.com/books/scanning-electronmicroscopy/pathogenic-attributes-of-non-candida-albicans-candida-species-revealed-by-sem

\section{INTECH}

open science | open minds

\section{InTech Europe}

University Campus STeP Ri

Slavka Krautzeka 83/A

51000 Rijeka, Croatia

Phone: +385 (51) 770447

Fax: +385 (51) 686166

www.intechopen.com

\section{InTech China}

Unit 405, Office Block, Hotel Equatorial Shanghai

No.65, Yan An Road (West), Shanghai, 200040, China

中国上海市延安西路65号上海国际贵都大饭店办公楼 405 单元

Phone: +86-21-62489820

Fax: $+86-21-62489821$ 
(C) 2012 The Author(s). Licensee IntechOpen. This is an open access article distributed under the terms of the Creative Commons Attribution 3.0 License, which permits unrestricted use, distribution, and reproduction in any medium, provided the original work is properly cited. 